\title{
Brachytherapy in the treatment of lung cancer - a valuable solution
}

\author{
Prof. Janusz Skowronek, MD, PhD \\ 'Brachytherapy Department, Greater Poland Cancer Center, 2Electroradiology Department, Poznan University of Medical Sciences, Poznan, \\ Poland
}

\begin{abstract}
The majority of patients with lung cancer are diagnosed with clinically advanced disease. Many of these patients have a short life expectancy and are treated with palliative aim. Because of uncontrolled local or recurrent disease, patients may have significant symptoms such as: cough, dyspnea, hemoptysis, obstructive pneumonia, or atelectasis. Brachytherapy is one of the most efficient methods in overcoming difficulties in breathing that is caused by endobronchial obstruction in palliative treatment of bronchus cancer. Efforts to relieve this obstructive process are worthwhile, because patients may experience improved quality of their life $(\mathrm{Q} o \mathrm{~L})$. Brachytherapy plays a limited but specific role in definitive treatment with curative intent in selected cases of early endobronchial disease as well as in the postoperative treatment of small residual peribronchial disease. Depending on the location of the lesion, in some cases brachytherapy is a treatment of choice. This option is fast, inexpensive, and easy to perform on an outpatient basis.

Clinical indications, different techniques, results, and complications are presented in this work.
\end{abstract}

Key words: brachytherapy, bronchial cancer, endoluminal, interstitial, lung cancer.

\section{Purpose}

Lung cancer is an ever-increasing health problem, smoking habits being responsible for a major increase in incidence in recent decades, and with five-year survival rates reaching only $10-12 \%$ during the last 20 years. The lung cancer failure rate remains unacceptably high, despite major advances over the past 40 years in the field of surgery, radiotherapy, and chemotherapy. In general, upon diagnosis, $25-30 \%$ of the non-small cell lung cancer (NSCLC) patients present with tumors confined to the lung (stage I or II), and only $40-50 \%$ of them can be targeted for cure; $30 \%$ have locally advanced disease (stage III), the remaining $40-45 \%$ have distant metastases (stage IV). Local recurrences after external beam radiotherapy (EBRT) occur in $60-70 \%$ of patients, and are responsible for $60 \%$ of the mortality due to respiratory failure, obstructive pneumonia, and sepsis. One of the most distressing symptoms for lung cancer patients is airway obstruction [1].

Brachytherapy (BT) plays an important role in the palliative treatment of obstructive disease, sometimes in conjunction with endobronchial laser therapy or stent implantation. Removal of endobronchial obstruction leads to quick improvement of clinical status and Quality of Life (QoL) [2-9]. Depending on the location of the lesion, in some cases, brachytherapy is a treatment of choice.
Efforts to relieve this obstructive process are worthwhile, because patients may experience improved QoL in hours or next days after treatment. In most cases, BT has a palliative aim due to advanced clinical stage [10-13]. Lack of clear consensus regarding the value of doses used in BT is the reason why different fraction doses are used in clinical treatment [1]. Due to bad performance status (ZubrodECOG-WHO score $\geq 2$ ), single high doses ranging from 10 Gy to 15 Gy are applied $[14,15]$. It seems that results in this procedure are similar to whenever doses were given weekly in two or three fractions. A single dose protocol is cost-saving procedure and more comfortable for patients [6]. On the other hand, weekly repeated treatment enable to achieve a better local control visualized with the use of bronchoscopy. Brachytherapy plays a limited but specific role in definitive treatment with curative intent in selected cases of early endobronchial disease, in selected advanced inoperable tumors combined with EBRT or in the postoperative treatment of small residual peribronchial disease [16]. A relatively rare indication is interstitial BT of peripheral tumors using permanent implants.

\section{General rules}

High-dose-rate brachytherapy (HDR-BT) of lung cancer is a well-established method for the local treatment of patients with inoperable tumors of the tracheobronchial 
system. In order to palliate symptoms and improve the quality of the remaining life for these patients, it is preferable to use a method that is relatively easy to perform and has minimal complications. Removal of the tumor mass by endoscopic biopsy forceps combined with cryosurgery, electrocautery, or laser ablation can achieve only limited clearance and short - term palliation, because the tumor kinetic is not altered [1]. Therefore, HDR-BT is the option of treatment endobronchial tumors, which can increase the efficiency of the control of malignant airway obstruction and the duration of palliation [17]. By placing a radioactive source near or in the tumor, a high dose of radiation is given to the tumor with the dose fall off in accordance of the inverse square law (Figure 1) [18]. The chance of damaging healthy tissues is reduced, since only a small amount of tissue receives therapeutic dose of radiation. The advantages of this technique over EBRT are: 1) it can be performed on an out-patient basis, 2) it decreases radiation exposure of the staff, 3) it permits optimization of dose distribution, 4) the treatment time is short, measured in minutes, 5) it reduces healthy tissue damages, caused by rapid dose fall off, which is particularly important for previously irradiated area.

As mentioned before, the leading clinical symptoms are dyspnoea, cough, haemoptysis, and pain. Some of patients show more than one symptom at diagnosis. The symptoms are qualified according to Speiser and Spratling scale for assessing palliative response in endobronchial brachytherapy [13]. An airway obstruction that is secondary to extensive primary or recurrent intrathoracic cancer, occurs frequently and creates devastating effects for many patients.

The definitive decision for brachytherapy is based on clinical examination, flexible bronchoscopy with precise documentation of the location and the amount of obstruction, and X-ray of the chest, which in some cases is supplemented by computed tomography or endobronchial echography. It is important to determine tumor extent as clearly as possible. For curative treatments, a comprehensive work up, as it is typical for lung cancer, should

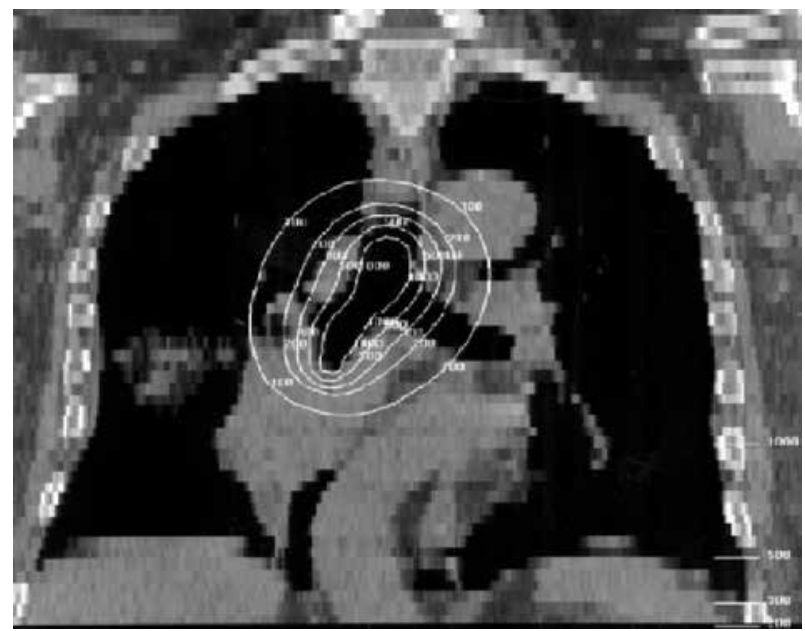

Fig. 1. Coronal reconstruction plane with superimposed dose distribution achieved with dose prescription relative to the mucosa. Rapid dose-fall visible [18] be performed, including in each case computed tomography (CT) and/or magnetic resonance imaging (MRI) of the chest and appropriate investigations such as positron emission tomography-computed tomography (PET-CT) to exclude distant and lymph node metastases.

\section{Clinical indications}

\section{Radical treatment}

Indications include:

1. Postoperative external radiotherapy and/or intraluminal brachytherapy of the bronchial stump after resection with positive resection margins [16].

2. Endobronchial brachytherapy with curative intent is considered as a boost for minor residual disease within a combined non-surgical radical approach. This may apply to small cell lung cancer after remission induction by chemotherapy and external radiotherapy or for non-small cell lung cancer as a boost after remission induction by external beam radiotherapy (with or without chemotherapy) $[19,20]$.

3. Definitive radiotherapy and brachytherapy $[21,22]$ or brachytherapy alone for small tumours (T1-T2) [3,4,23-27].

Commonly used treatment schemas are listed in Table 1.

\section{Palliative treatment}

Indications include:

1. Irradiation of tumors causing significant complaints, mainly dyspnoea caused by endobronchial obstruction, cough, haemoptysis, bronchopneumonia, and atelectasis $[1,6,7,10,30-33]$.

2. Brachytherapy in recurrences after surgery and/or EBRT $[1,6,7,30-33]$.

3. Irradiation of metastasis obturating bronchi. Brachytherapy can be performed as sole treatment or can be combined with EBRT (massive lymph node involvement), laser resection, implantation of prosthesis, and cryotherapy. ble 1.

Doses used in palliative HDR-BT are also listed in Ta-

\section{Contraindications}

General remark - decision must be taken individually. Most commonly cited contraindications for brachytherapy include peripheral tumor location, Pancoast tumor (in some cases interstitial brachytherapy can be used), external pressure (e.g. lymph node compression), contraindications for bronchoscopy (rare). General criteria include: $\mathrm{WHO} \geq 2$, lack of histopathological diagnosis (despite of poor general condition and intensive dyspnoea), tumor location not achieved during bronchoscopy $[6,7,17,34]$. In many cases brachytherapy is a saving-life procedure.

\section{Brachytherapy techniques [1]}

\section{Endobronchial brachytherapy}

In order to evaluate the airway, locate the tumor size, and define the site of obstruction, an initial bron- 
Table 1. Brachytherapy treatment schemas - indications, doses $[1,28,29]$

\begin{tabular}{|c|c|c|c|c|}
\hline Indications for brachytherapy & I clinical phase & Il clinical phase & III clinical phase & IV clinical phase \\
\hline $\begin{array}{l}\text { Radical combined treatment: } \\
\text { schema I; } \\
\text { Clinical stage T1-3 N1-3 MO }\end{array}$ & $\begin{array}{l}\text { EBRT: total dose } 44 \text { Gy in } 22 \mathrm{fr} . \\
\text { aa } 2 \text { Gy ( } 2 \text { a-p fields) }\end{array}$ & $1 \mathrm{fr} . \times 6 \mathrm{~Gy}$ & $\begin{array}{l}\text { EBRT } 16 \text { Gy in } 8 \mathrm{fr} \text {. } \\
\text { (changed fields) }\end{array}$ & $1 \mathrm{fr} . \times 6 \mathrm{~Gy}$ \\
\hline $\begin{array}{l}\text { Radical combined treatment: } \\
\text { schema II; } \\
\text { Clinical stage T1-3 N1-3 MO }\end{array}$ & $\begin{array}{l}\text { EBRT: total dose } 44 \text { Gy in } 22 \mathrm{fr} \text {. } \\
\text { aa } 2 \text { Gy ( } 2 \text { a-p fields) }\end{array}$ & $\begin{array}{l}\text { EBRT } 16 \text { Gy in } 8 \mathrm{fr} \text {. } \\
\text { (changed fields) }\end{array}$ & $\begin{array}{l}\text { HDR-BT - in } 1,3 \text { and } \\
5 \text { week of EBRT - } \\
3 \text { fr. } \times 10 \text { Gy }\end{array}$ & \\
\hline $\begin{array}{l}\text { Radical sole treatment, radio- } \\
\text { logically occult cancer T1-2NO }\end{array}$ & $\begin{array}{l}\text { Total dose } 36-42 \text { Gy in 6-7 fr. } \\
\text { with interval of 4-7 days } \\
\text { between fractions }\end{array}$ & & & \\
\hline $\begin{array}{l}\text { Radical treatment after surgery } \\
- \text { R2 }\end{array}$ & $\begin{array}{l}\text { After EBRT with total dose } \\
\text { of } 50-60 \mathrm{~Gy}\end{array}$ & $\begin{array}{l}\text { To consider increas- } \\
\text { ing the total use } \\
\text { using HDR-BT } \\
\text { HDR. Fr. dose from } \\
1 \times 6 \text { Gy till } 3 \mathrm{fr} \text { × } 6 \text { Gy } \\
\text { (18 Gy), depending } \\
\text { on EBRT dose }\end{array}$ & & \\
\hline $\begin{array}{l}\text { Radical treatment: stump } \\
\text { infiltration }\end{array}$ & \multicolumn{4}{|c|}{ Sole brachytherapy: $4 \mathrm{fr}$. of 7.5-10 Gy with interval of 4-7 days between fractions } \\
\hline \multirow[t]{3}{*}{ Palliative treatment } & \multicolumn{4}{|c|}{$\begin{array}{l}\text { Total dose } 18 \text { Gy in } 3 \text { fr. of } 6 \text { Gy with interval of 4-7 days - in patients treated earlier with EBRT - } \\
\text { dose }>50 \text { Gy }\end{array}$} \\
\hline & \multicolumn{4}{|c|}{$\begin{array}{c}\text { Total dose } 22.5 \text { Gy in } 3 \mathrm{fr} \text {. of } 7.5 \text { Gy with interval of } 4-7 \text { days - in patients not irradiated } \\
\text { or treated earlier with EBRT - dose }<50 \text { Gy }\end{array}$} \\
\hline & \multicolumn{4}{|c|}{$\begin{array}{c}1 \times 10 \text { Gy in case of WHO scale }>2 \\
\text { Sometimes dose can be repeated after few weeks, in cases with clinical remission or visible } \\
\text { during bronchoscopy }\end{array}$} \\
\hline
\end{tabular}

choscopy in local anesthesia is performed. Premedication is to provide anxiolytic drugs (e.g. midazolam $2.5 \mathrm{mg}$ subcutaneous), parasympatic blocking agent (often atropine $1 \mathrm{mg}$ ), and antitussive drug (often codeine). The catheters (one or two, either a 5- or 6-French) used to deliver the brachytherapy should be inserted through the brush channel of the bronchoscope (Figure 2 and 3 ). If a 6-French catheter is used, a large bronchoscope with brush channel diameter of at least $2.2 \mathrm{~mm}$ is required. If the HDR source has to pass tight curves, it is not possible with the 5-French catheter and the use of a 6-French catheter is necessary. If the bronchoscope is connected to a teaching head or a video monitor, the physician performing the application can visualize the lesion and the catheter. For the patient's comfort and to secure the catheter, the bronchoscope should be inserted through the nose. Then the afterloading catheter is inserted through the brush channel of the bronchoscope, passes through the tumor, and is lodged in one of the smaller bronchi. It is recommended to perform a fluoroscopic confirmation of the catheter's position. Then the distance between the proximal extent of the tumor and fixed structures such as the carina is measured. While the radiation oncologist pushes the catheter in, the assisting physicist or nurse (depending of local organization) carefully withdraws the bronchoscope. The use of fluoroscopy helps to keep the catheter in place during this push-pull technique of bronchoscope removal. The catheter should be secured with tape at the nose, and its position is marked in ink to alert the medical staff in case of displacement. In some situations (tumor localized in the carina of the main bronchi or smaller bronchi), multiple catheters (mostly two) are to be used. In such case, the procedure is repeated, making sure to clearly mark and describe each catheter. Localization $\mathrm{X}$-rays with radio-opaque dummy wires in the catheter are then obtained Figures 4 and 5 . To determine the length to be irradiated and the initial dwell position, the location of the obstruction and the target length are marked on the X-rays (in palliative treatment planning). The length to be irradiated usually covers the endobronchial tumor and $\pm 2.0 \mathrm{~cm}$ proximal and distal margins. The dose has been commonly prescribed at $1 \mathrm{~cm}$ from the source, although various points from 0.5 to $2 \mathrm{~cm}$ are used. If standard lengths and doses are used, the whole time of brachytherapy procedure can be shortened by starting treatment without any delay. When a single catheter is used and if there is minimal curvature in the area to be irradiated, it is possible to minimize the treatment planning time by using pre-calculated standard treatment plans for $3-10 \mathrm{~cm}$ lengths to be irradiated from 5 to $10 \mathrm{~Gy}$ at $1 \mathrm{~cm}$ from the source using equal dwell times. However, individualized image-based treatment planning must be performed if multiple catheters are used $[35,36]$. Examples of implanted catheters in bronchi are presented in Figures 6 and 7. 


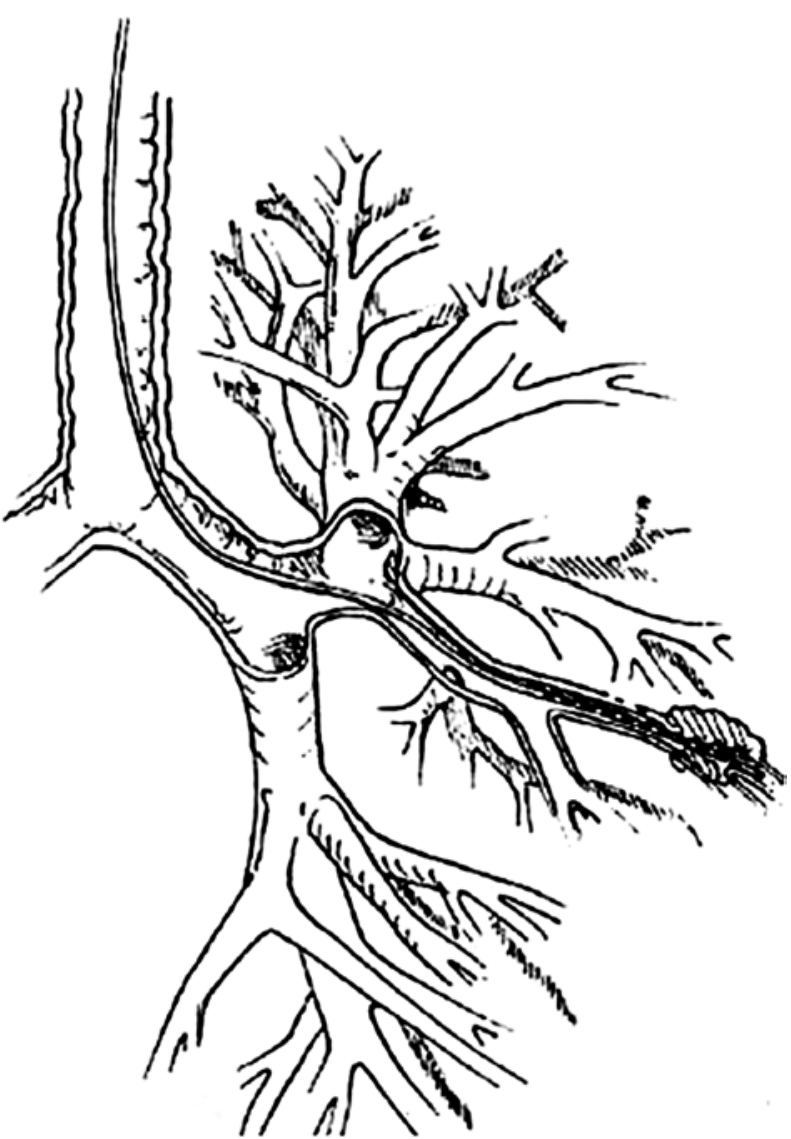

Fig. 2. Endobronchial brachytherapy with a small $(<2 \mathrm{~mm}$, 5- to 6-French) endobronchial applicator, entered in a tertiary bronchus for treatment [17]

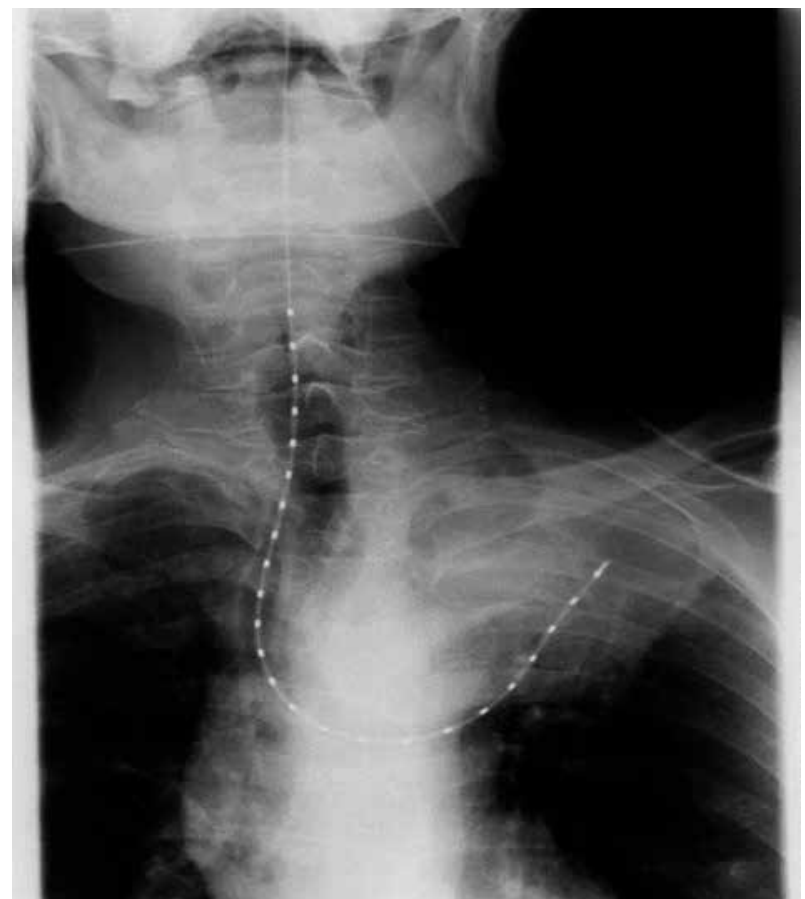

Fig. 4. Endobronchial applicator with metal marker inside used for treatment planning, tumor localized in left upper lobe bronchus, X-ray picture [own material]

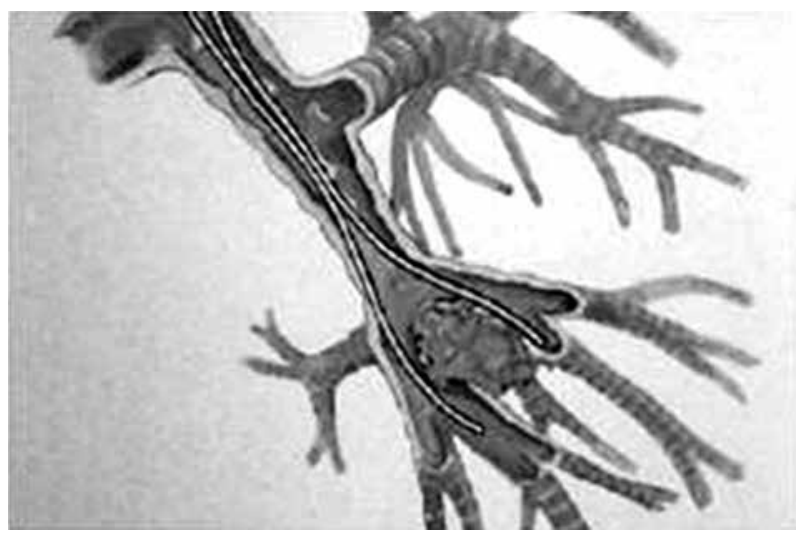

Fig. 3. Intraluminal technique with two tubes in bronchus brachytherapy: schematic anatomical diagram showing the ideal situation with two tubes encompassing a small tumor located in the carina of two tertiary bronchi in the left lower lobe [17]

\section{Interstitial brachytherapy [1]}

Permanent implants brachytherapy

In peripheral tumors, inoperable for different reasons and inaccessible in bronchofiberoscopy, some percutaneous techniques may be applied [37-44]. This techniques are used occasionally, mainly in some academic centers in US and Japan. Patients affected by carcinoma of the lung many times have limited pulmonary capacities, either from long-term damage due to a significant past history of smoking or any one of a number of physiologic reasons. These patients may not tolerate traditional thoracotomy and lobectomy. Potential treatment options for

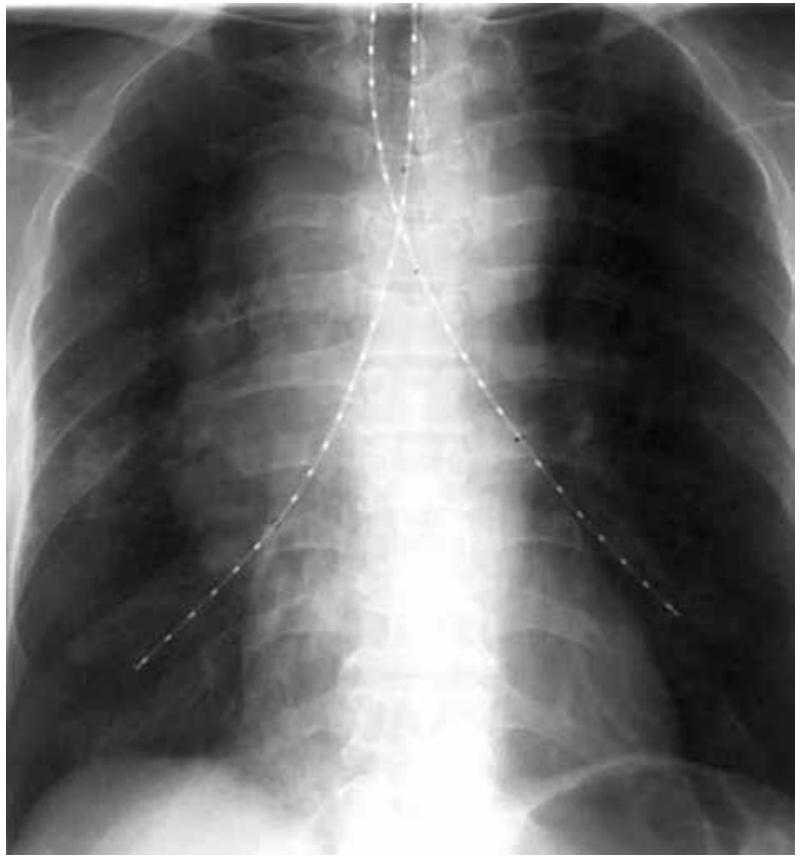

Fig. 5. Bilateral lung cancer - endobronchial applicators with metal markers inside used for treatment planning, tumor localized infiltrating carina and both main bronchus, X-ray picture [own material] 

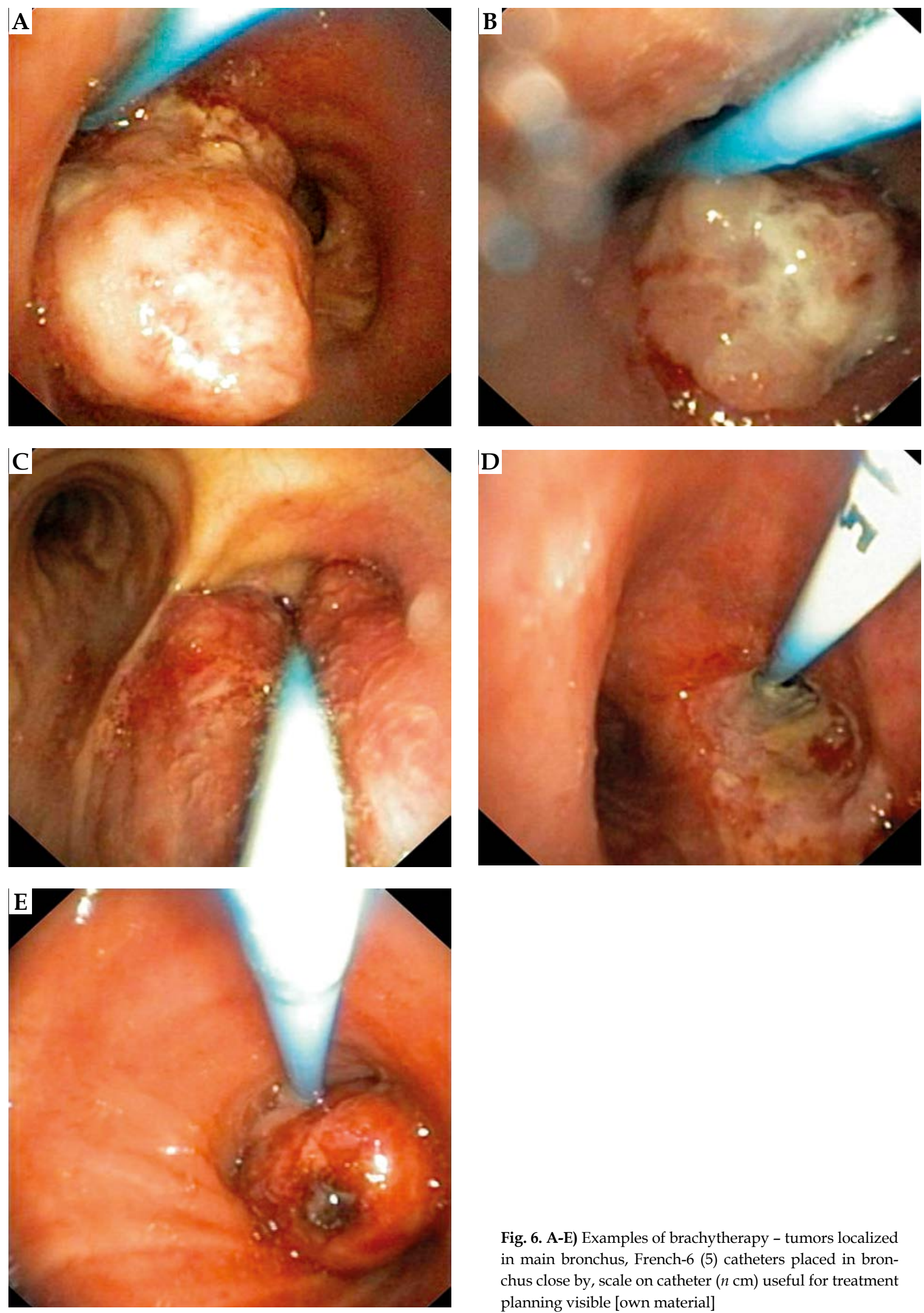

Fig. 6. A-E) Examples of brachytherapy - tumors localized in main bronchus, French-6 (5) catheters placed in bronchus close by, scale on catheter $(n \mathrm{~cm})$ useful for treatment planning visible [own material] 

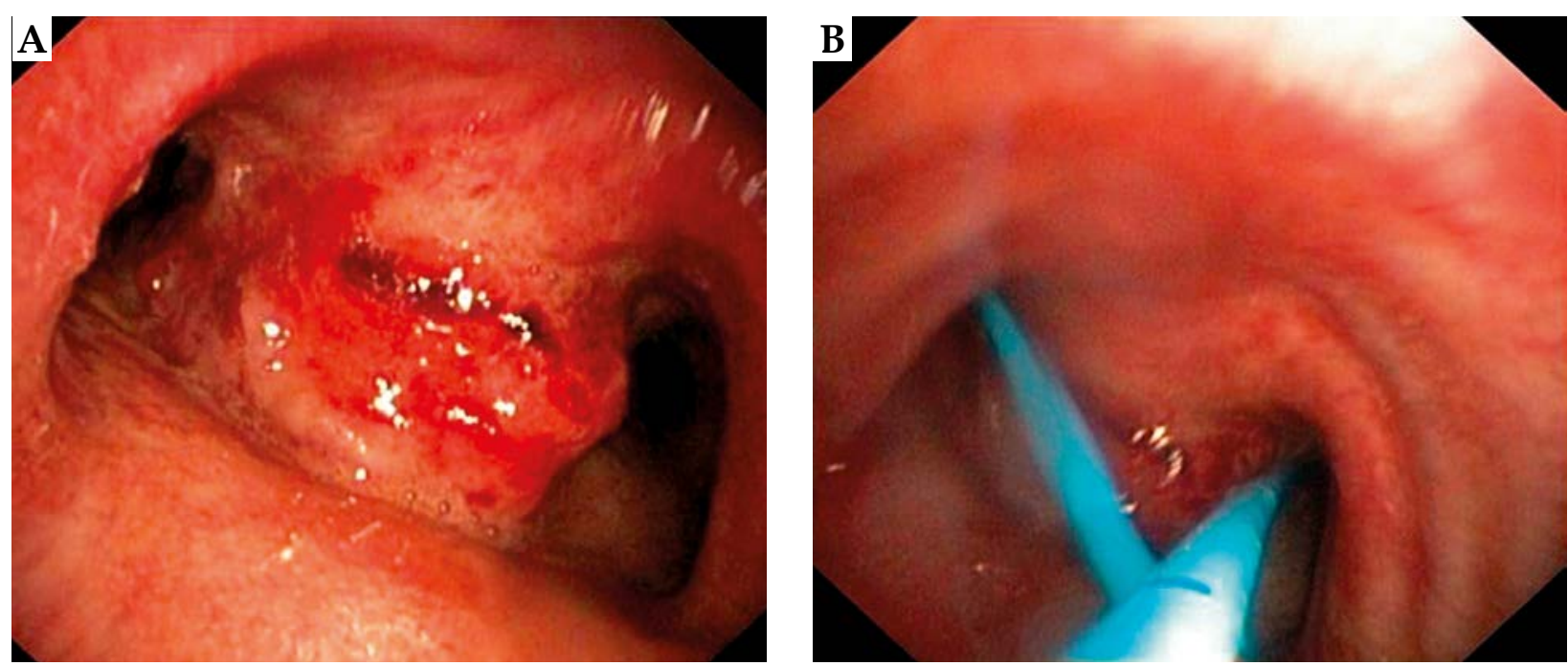

Fig. 7. A, B) Tumor infiltrating carina and both main bronchi before application and after application of two brachytherapy catheters. In this cases, irradiated area includes carina and both main bronchi [own material]

these high-risk or medically inoperable patients include sublobar resection with or without ${ }^{125}$ I lung brachytherapy [44]. Permanent implantation of ${ }^{125}$ I seeds can be safely used in areas where the total dose of radiation received is usually limited by significant late toxicity, such as directly on pulmonary tissue or in close proximity to the spinal cord. Published studies describe the use of intraoperative, permanent implantation of ${ }^{125} \mathrm{I}$ seeds for the treatment of thoracic malignancies. In early-stage of NSCLC, the addition of intraoperative brachytherapy to sublobar resection improved predicted rates of local control, and overall survival compared to sublobar resection alone. In more advanced disease with residual tumor or positive lymph nodes at surgery, the addition of thoracic brachytherapy resulted in favorable rates of local control and survival. When planar ${ }^{125} \mathrm{I}$ implants were placed following resec-

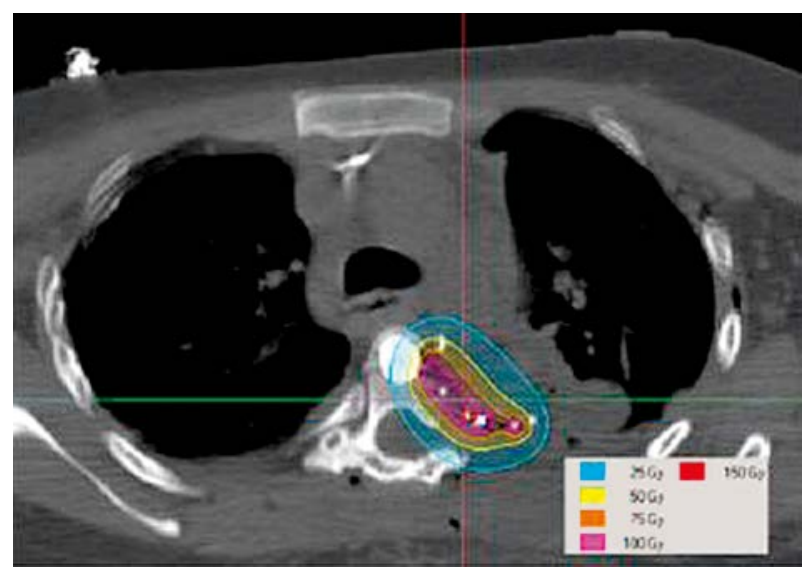

Fig. 8. Axial isodose distributions for a planar permanent ${ }^{125}$ I paraspinal implant. Intraoperative ${ }^{125}$ I seed placement has been used in conjunction with sublobar resection in patients with lung cancer who are medically unfit for lobar resection. This technique is currently being evaluated in the USA in a multi-institution randomized prospective trial by the American College of Surgeons Oncology Group (ACOSOG) Z4032 [41] tion of metastatic and locally invasive paraspinal tumors, excellent local control rates with minimal toxicity were seen, despite high localized doses to the spinal cord [37]. Most frequently isotopes ${ }^{125} \mathrm{I},{ }^{103} \mathrm{Pd}$, and ${ }^{131} \mathrm{Cs}$ (dose rate 0.01 to $0.3 \mathrm{~Gy} / \mathrm{h}$ ) are used (Figure 8 and 9). Physical characteristics of them shows low-energy, small size, and short half-life decay time. Treatment time doesn't exceed 30-45 minutes, isotopes are implanted into tumor in total analgesia. Special elastic applicators are used for implantation. Nominal total activity is $0.5-1 \mathrm{~Gy} / \mathrm{h}$, total summarized dose is 100-160 Gy in CTV (clinical target volume). Recommended diameter of the tumor should not exceed $5-6 \mathrm{~cm}$. This technique is used in subpleural, peripheral tumors or Pancoast tumor [1].

\section{Temporary high-dose-rate brachytherapy}

An alternative for permanent brachytherapy could be interstitial brachytherapy with the use of HDR sources. Sometimes the costs are the most important reason for choosing this technique. If permanent implants are not available, in one procedure elastic applicators (using steel needles first) are inserted into tumor tissue. After preparing a treatment plan, a patient is connected to the HDR unit and irradiated. High-dose-rate brachytherapy is used in tumors smaller than $2 \mathrm{~cm}$ in diameter. One fraction of 10-20 Gy was used so far (Figure 10). After not complete tumor excision, elastic applicators can be fixed in tumor bed. Three to seven days after surgery HDR-BT is performed, 3-4 fractions of 4-5 Gy are used (one fraction daily) $[40,41,45,46]$.

\section{Target volume and planning}

The intraluminal target volume is usually determined by bronchoscopy findings. Proximal and distal margins of the intraluminal gross tumor volume must be carefully assessed and the distance from both margins to the tracheal carina measured. In completely obstructing lesions, assessment of the distal margin may not be possible by endosco- 

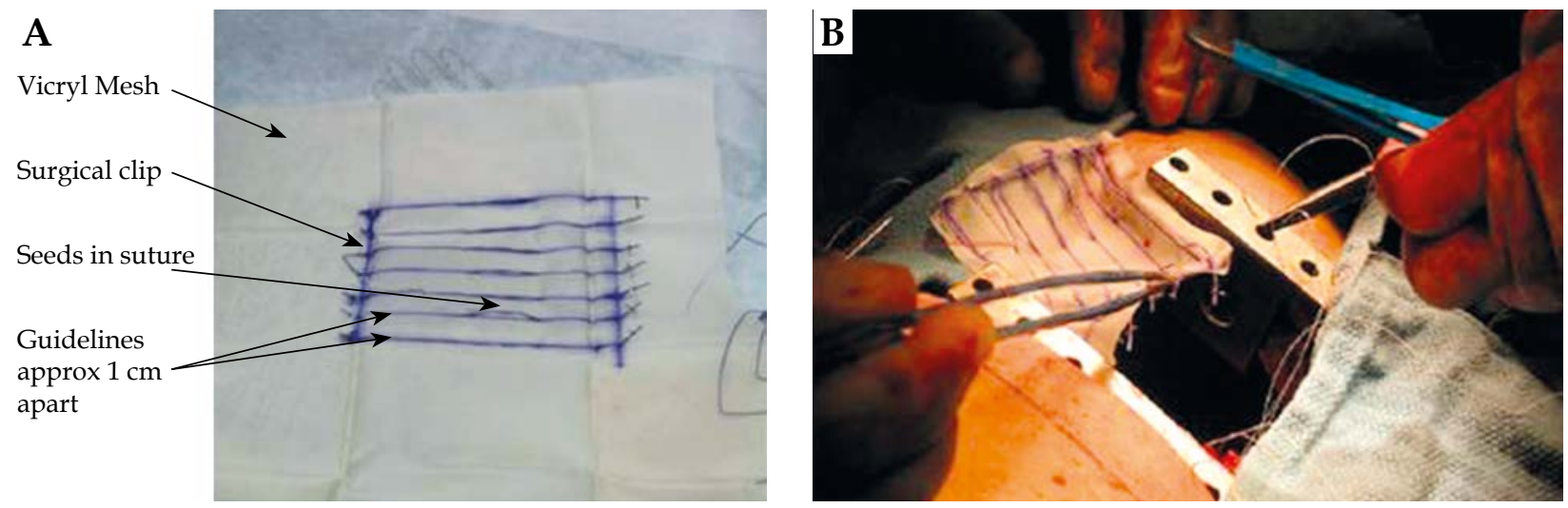

Fig. 9. A) Planar implant made using ${ }^{125}$ I seeds in suture within a Vicryl mesh. B) Completed implant being placed into mediastinum using long-handled tools. The seeds will be straightened to give optimal dosimetry before lung reinflation [41]

py. Additional information from chest X-ray or CT imaging may be helpful to estimate the length of the obstruction.

Since in palliative brachytherapy the extraluminal part of the tumor is usually rather large, and therefore not treatable by brachytherapy, there is only limited need for a precise assessment of the extraluminal tumor dimensions for target definition. In the longitudinal direction, a safety margin of $2 \mathrm{~cm}$ is usually added to both sides of the macroscopic tumor to define the target volume. If there is a doubt regarding the distal margins, an extra 2 to $3 \mathrm{~cm}$ should be added to insure covering the whole endobronchial tumor extension.

In contrast, in curative brachytherapy, the whole area at risk must be included. This is the wall in superficial spreading tumors, and tumor depths of a few $\mathrm{mm}$ in limited T1-tumours. Autofluorescent bronchoscopy is very helpful in this case, determining exactly the margins of the infiltrating tumor. The same applies for adjuvant treatment after radical resection with positive margins, and for minimal residual disease after chemotherapy and/or external beam therapy.

Computed tomography scans with the applicator in place allow a better estimate of the tumor topography in relation to the applicator. CT-based planning enabling more precise target volume definition and volumetric dose information can improve the therapeutic ratio of brachytherapy (Figures 11). Potential benefits and limitations of using CT-assisted brachytherapy can be characterized by the following:

1. Use of CT imaging to supplement the findings of bronchoscopy, particularly in determining the distal extent of the target volume.

2. Visualization of the position of the applicator in relation to the target volume.

3. Facilitation of dose prescription to the bronchial mucosa by identifying the position of branching of the different sub-segments of the bronchial tree, and allowing the use of actual measurements of the diameter of each segment.

4. Visualization and delineation of the esophagus, particularly in tumors of the trachea and the left primary bronchus.

5. Generation of a 3D dosimetric database for correlation with toxicity $[18,25,35,36,47-49]$

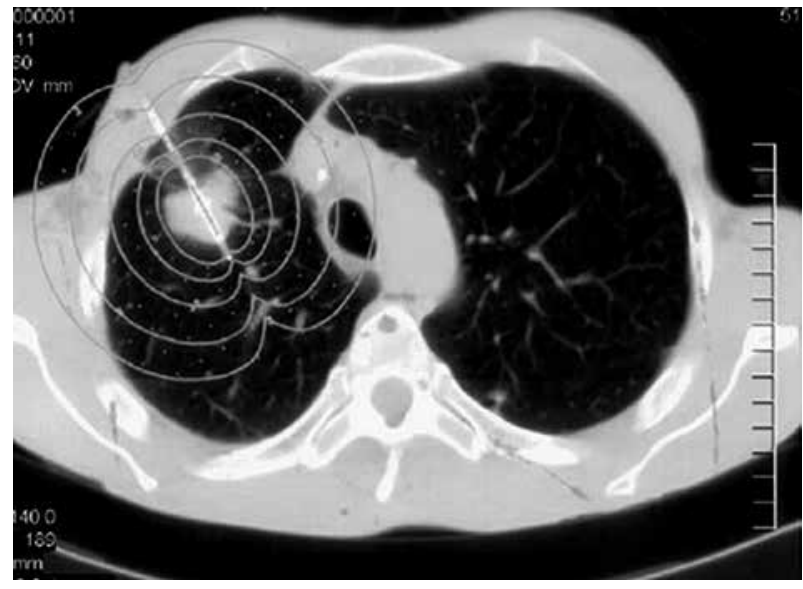

Fig. 10. Lung metastasis of colorectal carcinoma treated with a single brachytherapy catheter. The inner isodose represents 20 Gy. Note the steep gradient with the outer isodose, illustrating a dose of 3 Gy [46]

\section{Results}

\section{Monotherapy - radical treatment}

Survival after treatment in M0 patients seems to be dependent on the degree of remission achieved. Macha et al. [50] reported a mean survival of 7.5 months in M0 patients ranging from 8.5 months in PR to only 2.5 months $(\mathrm{NC}+\mathrm{PD})$. However, the impact of endobronchial BT on survival is still debatable. Speiser and Spratling [13] reported that patients treated with curative intent with EBRT and a BT boost did not have a significantly longer survival than patients treated with EBRT alone.

The Munich group [20] conducted a prospective randomized trial on central lung tumors. Patients received 60 Gy with EBRT and received either no further treatment or a boost of two 4.8 Gy endobronchial HDR fractions at $10 \mathrm{~mm}$ from the source axis. The median local control in these advanced cases was increased with the boost from 12 weeks to 21 weeks $(p=0.052)$. In the 68 patients with squamous cell carcinoma, the impact of the boost was more important with a significant increase in local control $(p=0.007)$. Survival time seemed to be lon- 

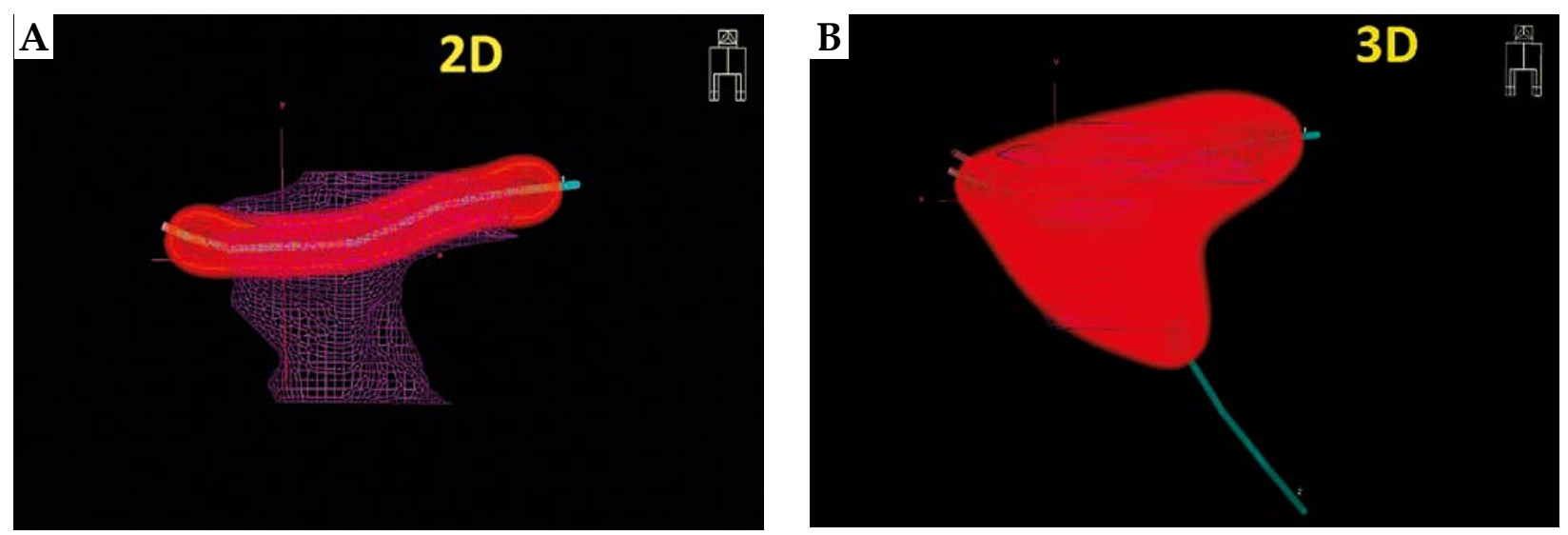

Fig. 11. A) Patient with two catheters inserted during regular 3D planning. For the 2D planning only one of them would be used (the one inserted into the bronchus with visible obturation). Comparison of GTV coverage by the $90 \%$ isodose achieved in 2D planning system. Legend: purple triangles - GTV volume, orange cylinder - 2D 90\% isodose, blue - catheter. B) Patient with two catheters inserted. Comparison of GTV coverage by the $90 \%$ isodose achieved in 3D planning system. Legend: purple triangles - GTV volume, orange volume - 3D 90\% isodose, blue - catheters [36]

ger (40 vs. 33 weeks) but did not reach statistical significance $(p=0.09)$.

A specific subgroup to be considered is radiographically occult endobronchial tumors (ROEC) in medically inoperable patients. Although these cases are rare, they could be the best indications for endobronchial BT.

Doing both for EBRT and BT with curative intent may bring advantage, because in these cases BT might be able to cover the whole ROEC target volume. The reported outcome in this selected group of patients is encouraging (Table 2).

\section{Combined radical treatment with external beam radiotherapy}

Fuwa et al. [21] treated 17 cases of ROEC with the combination of EBRT and intraluminal low-dose-rate brachytherapy (LDR-BT). Although doses of EBRT and LDR-BT varied considerably, no severe late toxicity was observed and 5-year cause specific survival was about $90 \%$.

In a larger Japanese series reported by Saito et al. [22], 64 patients with ROEC (68 lesions) were treated with external beam RT to 40 Gy followed by 25 Gy LDR intraluminal brachytherapy. Five year survival was $72.3 \%$, and disease free survival $87.3 \%$ with acceptable acute tox- icity with $6 \%$ grade 2 pneumonitis and $29 \%$ grade 1 late stenosis, but without any grade 2 or greater deterioration of respiratory function due to radiotherapy. Nine (14\%) local recurrences were seen, five of them rescued by surgery and EBRT.

In Europe, studies were performed on medically inoperable patients with HDR-BT alone [4,23-27]. Most patients received 3-6 fractions of 7-10 Gy at $10 \mathrm{~mm}$ from the source axis. Over $80 \%$ had a complete response and a good survival outcome. Local recurrences were noted in $5-40 \%$ of cases (Table 3). Acute toxicity was tolerable but fatal hemoptysis and bronchial necrosis were reported, especially in those patients who received more than $35 \mathrm{~Gy}$ HDR brachytherapy [24-27]. Groups of patients qualified for combined treatment (EBRT and BT) are heterogeneous (Table 3).

\section{Palliative endoluminal brachytherapy}

A lot of investigators have used a range of prescription points and fractional doses, which could not be directly compared.

As symptom relief is the main endpoint in palliative treatment, results should be described accordingly. There are subjective and objective methods for assessing

Table 2. Endobronchial high-dose-rate monotherapy for radiographically occult endobronchial carcinoma

\begin{tabular}{|c|c|c|c|c|c|c|c|}
\hline Author & $n$ & Clinical stage & $\begin{array}{l}\text { Brachytherapy schedule } \\
\text { (fr., dose) }\end{array}$ & $\begin{array}{c}\text { Reference } \\
\text { point }\end{array}$ & OFS (\%) & CR (\%) & LR (\%) \\
\hline Tredaniel et al. [27] & 14 & Limited to wall & $3 \times 7$ Gy & $10 \mathrm{~mm}$ & - & 84 & 14 \\
\hline Ardiet et al. [23] & 28 & $<10$ mm CT neg & 3-5 × 7 Gy & $10 \mathrm{~mm}$ & - & 84 & 24 \\
\hline Perol et al. [26] & 19 & < 10 mm CT neg & $3-5 \times 7$ Gy & $10 \mathrm{~mm}$ & $58-2 y$ & 83 & 5 \\
\hline Taulelle et al. [4] & 22 & Limited to wall & $3-5$ × 7-10 Gy & $10 \mathrm{~mm}$ & $46-3 y$ & 96 & 18 \\
\hline Hennequin et al. [24] & 73 & $<20 \mathrm{~mm} \mathrm{CT}$ pos & $5-6 \times 7$ Gy & $5-15 \mathrm{~mm}$ & $45-2 y$ & NA & 41 \\
\hline Marsiglia et al. [25] & 34 & $2-40 \mathrm{~mm}$ & 6 × $5 \mathrm{~Gy}$ & $5-10 \mathrm{~mm}$ & $78-2 y$ & 94 & 27 \\
\hline
\end{tabular}


Table 3. Curative high-dose-rate brachytherapy combined with external beam radiotherapy: in IIIA and IIIB lung cancers

\begin{tabular}{|c|c|c|c|c|c|c|}
\hline Author & $n$ & Clinical stage & EBRT (Gy) & $\begin{array}{c}\text { Brachytherapy } \\
\text { schemas (fr., dose) }\end{array}$ & LC (\%) & OFS (\%) \\
\hline Mantz et al. [30] & 39 & $\mathrm{~T} 1-2 \leq 5 \mathrm{~cm}$ & $54-75.6$ & $\begin{array}{c}\text { Trial: } \\
\text { 1. 2-4 × 5-7 Gy } \\
\text { 2. no BT }\end{array}$ & $\begin{array}{c}5 \mathrm{y}: \mathrm{EBRT}+\mathrm{BT}- \\
58 \% \\
\text { EBRT }-32 \%\end{array}$ & - \\
\hline Huber et al. [51] & 68 & $\begin{array}{l}\text { Advanced central } \\
\text { lung tumors }\end{array}$ & 60 & $\begin{array}{c}\text { Trial: } \\
\text { 1. } 2 \text { × } 4.8 \mathrm{~Gy} \\
\text { 2. no BT }\end{array}$ & $\begin{array}{l}5 \text { vs. } 3 \text { mth } \\
(p=0.052)\end{array}$ & $\begin{array}{c}10 \text { vs. } 8 \text { mth } \\
(p=0.09)\end{array}$ \\
\hline Reddi et al. [52] & 32 & $\||| A-\| B$ & 60 & $3 \times 7.5 \mathrm{~Gy}$ & - & $8 \mathrm{mth}$ \\
\hline Aygun et al. [53] & 62 & $\|I I A-\| I B$ & $50-60$ & $3-5 \times 5$ Gy & - & $13 \mathrm{mth}$ \\
\hline Mehta et al. [54] & 22 & $\|I \mid A-\| B$ & 60 & $4 \times 4$ Gy & - & $8.5 \mathrm{mth}$ \\
\hline Chang et al. [55] & 54 & $\|I \mid A-\| B$ & $20-70$ & $3 \times 7 \mathrm{~Gy}$ & - & - \\
\hline Cotter et al. [56] & 65 & $\||| A-\| B$ & $55-66$ & $2-4 \times 2.7-10 \mathrm{~Gy}$ & $86 \%$ & $8 \mathrm{mth}$ \\
\hline Speiser and Spratling [13] & 50 & $\| I|I| B$ & 60 & $3 \times 7.5-10$ & $80 \%$ & $11 \mathrm{mth}$ \\
\hline Kohek et al. [57] & 39 & III & $50-70$ & $1-5 \times 5.6$ & $67 \%$ & $13 \mathrm{mth}$ \\
\hline Zajac et al. [58] & 24 & III & $50-61.2$ & $3 \times 5-10$ & $82 \%$ & $12 \mathrm{mth}$ \\
\hline
\end{tabular}

LC - local control, OFS - overall free survival, BT - brachytherapy, LDR - low-dose-rate, MDR - medium-dose-rate, HDR - high-dose-rate, EBRT - external beam radiation therapy, $y$-years, Gy-Grey, mth-months, fr. - fraction

the efficacy of endobronchial brachytherapy. According to several large series published [13,50,55,57,59], overall symptom relief is achieved in more than two thirds of the patients. For example, in Kohek's series [57] relief from cough was obtained in 51/73, from dyspnea in 42/63, from hemoptysis in $6 / 8$ patients. Improvement in general condition (Karnofsky scale) was noted in 69.5 to $76.5 \%$.

Partial remission as assessed by objective measurements was achieved in 101/188, minor response in 25/188, no change in $29 / 188$, progressive disease in $33 / 188$ patients. Speiser and Spratling found a change in mean obstruction score (from bronchoscopy findings) before and after brachytherapy in 65 to $71 \%$ of the treated subgroups (curative, palliative, recurrent) [13].

Similarly, Gustafson et al. [31] noted significant clinical improvement in $74 \%$ of 38 symptomatic patients treated with $21 \mathrm{~Gy}$ at $1 \mathrm{~cm}$, given in three HDR applications over 3 weeks. In patients without prior irradiation, there was a tendency for higher percentage of clinical and radiographic response. Authors concluded that a significant proportion of patients can be reduced asymptomatically for the duration of their lives. In one of the largest published studies, there were 648 patients with endobronchial tumor treated with two different protocols of HDR brachytherapy [6].

Significant and durable clinical and radiographic responses could be obtained in patients with symptoms, despite prior radiation or metastatic and non-bronchogenic primary disease. There was no statistically important difference in the results between the two groups of patients treated with different doses. The complication rate compared favorably with those reported from other institutions. The median survival time of 5.9 months was consistent with the advanced stage of this population. Multivariate analysis showed that the grade of remission after treatment, clinical stage, and performance status had maintained significance for survival time as well as for treatment response. Some published results are presented in Table 4.

\section{Endobronchial recurrence after external beam radiotherapy - endoluminal brachytherapy}

A special indication for endobronchial brachytherapy is recurrent endobronchial disease after EBRT in selected patients. Endobronchial radiation therapy, especially in previously irradiated area with dose limitations set by radiation tolerance of normal tissue, represents a therapeutic option with several advantages over conventional external beam radiotherapy and other therapeutic modalities. By placing a radioactive source near or in the tumor, a high dose of radiation is given to the tumor with the dose fall off in accordance with the inverse square law. The chance of damaging healthy tissues is reduced, since only a small amount of tissue receives therapeutic radiation dose [1]. Speiser and Spratling [13] reported the same palliative effect and survival outcome in these recurrences, as was seen in patients treated primarily with palliative intent. Gauwitz et al. [62] reported on 24 patients with recurrent disease after external beam RT of at least 55 Gy. All patients had an ECOG performance less than 2. Treatment consisted of 2 HDR fractions of 15 Gy at $6 \mathrm{~mm}$ (corresponding to $9 \mathrm{~Gy}$ at $10 \mathrm{~mm}$ ). Symptomatic relief was obtained in 21/24 (88\%), and relief from atelectasis in $15 / 18(83 \%)$, lasting for 26 weeks on the average (7-40 weeks). Only 1 of 24 patients died of hemoptysis. Micke et al. [69] reported the results of HDR brachytherapy in 16 patients with recurrent lung cancer after EBRT (50-60 Gy). The recurrences were treated using 2 to 4 applications of 5 to 6 Gy each. The median period of remis- 
Table 4. Palliative high-dose-rate brachytherapy of lung cancer - treatment results

\begin{tabular}{|c|c|c|c|c|c|c|}
\hline Author & $n$ & $\begin{array}{c}\text { HDR } \\
\text { doses }\left(^{\star}\right)\end{array}$ & $\begin{array}{c}\text { Clinical } \\
\text { improvement (\%) }\end{array}$ & $\begin{array}{c}\text { Chest X-ray } \\
\text { improvement (\%) }\end{array}$ & $\begin{array}{c}\text { Bronchoscopy } \\
\text { improvement (\%) }\end{array}$ & Median OS \\
\hline Bedwinek et al. [60] & 38 & $3 \times 6$ & 76 & 64 & 82 & $10 \mathrm{mth}$ \\
\hline Jacobson et al. [61] & & $3 \times 6$ & 74 & - & 65 & - \\
\hline Gauwitz et al. [62] & 24 & - & 88 & - & 88 & $8 \mathrm{mth}$ \\
\hline Sutedja et al. [19] & 31 & $3 \times 10$ & 82 & - & - & $7 \mathrm{mth}$ \\
\hline Burt et al. [63] & 50 & $1 \times 15-20$ & $50-86$ & 46 & 88 & - \\
\hline Miller and Phillips [64] & 88 & $3 \times 10$ & - & - & 80 & - \\
\hline Aygun et al. [53] & 62 & $3-5 \times 5$ & - & 36 & 76 & - \\
\hline Mehta et al. [65] & 31 & $4 \times 4$ & 88 & $71-100$ & 85 & - \\
\hline Speiser and Spratling [66] & $\begin{array}{l}144 \\
151\end{array}$ & $\begin{array}{l}3 \times 10 \\
3 \times 5-7\end{array}$ & $85-99$ & - & 80 & - \\
\hline Zajac et al. [58] & 82 & $1-5 \times 10$ & 82 & - & 74 & - \\
\hline Chang et al. [55] & 76 & $3 \times 7$ & $79-95$ & - & 87 & - \\
\hline Delclos et al. [67] & 81 & $1-2 \times 15$ & 85 & 75 & 80 & - \\
\hline Gollins et al. [59] & 406 & $1 \times 10-20$ & - & - & 65 & - \\
\hline Macha et al. [50] & 365 & $3-4 \times 5$ & 66 & - & - & - \\
\hline Kelly et al. [68] & 175 & $2 \times 15$ & 66 & - & 78 & $6 \mathrm{mth}$ \\
\hline Skowronek et al. [6] & $\begin{array}{l}303 \\
345\end{array}$ & $\begin{array}{l}3 \times 7.5 \\
1 \times 10\end{array}$ & $\begin{array}{c}88.4 \\
(14.5 \%-1 \text { year })\end{array}$ & - & No difference & $3.7 \mathrm{mth}$ \\
\hline
\end{tabular}

${ }^{*}$ Number of fractions and fraction size in Gy, HDR - high-dose-rate brachytherapy, mth - months, OS - overall survival, fr. - fraction

sion was 4 months, whereas the median survival time was 9 months. Ornadel et al. [70] have undertaken a prospective analysis of symptom response, duration response, and prognostic factors in 117 patients treated with brachytherapy. A single dose of 15 Gy was applied. Ninety-two patients had received previous EBRT. The median survival time was 12 months. There was no correlation between the total dose of the prior EBRT and the survival rate or rate of fatal hemoptysis. In the Bedwinek et al. [60] series, 38 patients were treated with high dose rate endobronchial brachytherapy to palliate symptoms caused by endobronchial recurrence of previously irradiated (> $50 \mathrm{~Gy}$ ) lung cancer. Twenty-nine (76\%) patients had symptomatic improvement in response to a dose of $18 \mathrm{~Gy}$, given in $3 \mathrm{HDR}$ sessions weekly. The median duration of symptoms relief was 7.5 months. Bronchoscopy carried out 3 months after brachytherapy revealed that $41 \%$ had complete regression and another $41 \%$ had partial regression.

In selected small tumors, palliation may be more successful and long term survivors have been described. At Manchester's Christie Hospital, 37 patients with small tumors less than $2 \mathrm{~cm}$ were treated with a single dose of 15-20 Gy delivered at $1 \mathrm{~cm}$ from the source [59]. Symptom relief lasting for up to 12 months after treatment was obtained for hemoptysis in $96 \%$, relief of pulmonary collapse in $69 \%$, relief of cough in $55 \%$, and of dyspnea in $52 \%$. The median survival was 709 days, 2-year survival (49.4\%), and 5-year survival (14.1\%).

\section{Interstitial brachytherapy}

In early-stage of NSCLC, the addition of intraoperative brachytherapy to sublobar resection improved predicted rates of local control, and overall survival compared to sublobar resection alone. In more advanced disease with residual tumor or positive lymph nodes at surgery, the addition of thoracic brachytherapy resulted in favorable rates of local control and survival. When planar ${ }^{125} \mathrm{I}$ implants were placed, following resection of metastatic and locally invasive paraspinal tumors, excellent local control rates with minimal toxicity were seen, despite high localized doses to the spinal cord $[1,37]$.

Interstitial brachytherapy as an independent radical brachytherapy was used so far in small groups of patients. Three presented in Table 5 reports come from studies of one group of researchers. They described in each of these papers different groups of patients in clinical stage I and II, III and a group of patients with Pancoast tumor [39,40,46]. In the last group, especially noteworthy are good clinical results: $70 \%$ local control in 5-years follow-up, 10 years survived (20\% of patients) [39]. Published treatment results are presented in Table 5. In Figures 8-10, examples of treatment plan using ${ }^{125} \mathrm{I}$ are presented.

\section{Side effects}

Acute side effects related to the treatment procedure itself are reported in 1-3\% of applications consisting of 
Table 5. Clinical results of interstitial brachytherapy

\begin{tabular}{|c|c|c|c|c|}
\hline Author & $\begin{array}{l}\text { Number of patients, } \\
\text { clinical stage }\end{array}$ & Isotope, technique & LC & OS \\
\hline Hilaris et al. [46] & 322 , stage III - NO & ${ }^{125}$ I, residual tumor after surgery & $71 \%-2 y$ & $20 \%-2 y$ \\
\hline Hilaris et al. [39] & 55 , stage I and II & 125I, 24 patients - additional EBRT & $\begin{array}{c}\text { T1NO }-100 \%(5 \mathrm{y}) \\
\text { T2N0 }-70 \% \\
\text { T1-2N1-71\% } \\
\end{array}$ & $33 \%-5 y$ \\
\hline Hilaris et al. [40] & $\begin{array}{l}\text { 127, superior sulcus } \\
\text { tumors - Pancoast } \\
\text { tumors }\end{array}$ & $\begin{array}{l}\text { Preoperative EBRT + partial resection + } \\
\qquad{ }^{125} \mathrm{I} \text { or }{ }^{192} \mathrm{Ir}\end{array}$ & $70 \%-5 y$ & $20 \%-10 y$ \\
\hline $\begin{array}{l}\text { Fleishman et al. } \\
\text { [38] }\end{array}$ & stage I & 125 & $71 \%-1 y$ & median - 15 mth \\
\hline Burt et al. [63] & $\begin{array}{l}\text { stage III: } \\
\text { 1. S only - } 49 \\
\text { 2. S incomplete + } \\
\text { BT - } 33 \\
\text { 3. BT only - } 101\end{array}$ & 125 & - & $\begin{array}{c}2 y ; 3 y: \\
1-29 \%, 21 \% \\
2-30 \%, 22 \% \\
3-21 \%, 9 \%\end{array}$ \\
\hline Chen et al. [42] & $\begin{array}{l}\text { 23, I stage NSCLC, } \\
\text { high risk group }\end{array}$ & $\begin{array}{l}\text { Video-assisted thoracoscopic resection } \\
\qquad(\text { VATR })+{ }^{125} \mid\end{array}$ & $\begin{array}{l}\text { Median follow-up- } \\
11 \mathrm{mth}\end{array}$ & $\begin{array}{l}3 \text { - metastases } \\
3 \text { - perioperative } \\
\text { deaths } \\
1 \text { - recurrence }\end{array}$ \\
\hline D’Amato et al. [43] & 14, T1NO, NSCLC & $\begin{array}{l}\text { Video-assisted thoracoscopic (VATS) } \\
\text { wedge; resection }+{ }^{125} \text { I (Vicryl) }\end{array}$ & $\begin{array}{l}\text { Median follow-up } \\
-7 \mathrm{mth}\end{array}$ & No recurrences \\
\hline Trombetta et al. [44] & 278 & $\begin{array}{l}\text { Gross total resection of a non-small cell lung } \\
\text { cancer using segmental resection, wedge } \\
\text { resection, or sublobar resection }+{ }^{125} \mid\end{array}$ & $\begin{array}{l}\text { Median follow-up- } \\
45.3 \mathrm{mth}\end{array}$ & - \\
\hline
\end{tabular}

pneumothorax, bronchospasm, hemoptysis, pneumonia, cardiac arrhythmia, cardiac arrest, or hypotension. Some problems arise in assessing the incidence of late complications occurring weeks to months after brachytherapy, as it is sometimes difficult to differentiate between complications due to tumor progression or from radiotherapy. Examples of late necrosis are presented in Figures 12.

Risk factors for severe hemoptysis include: received high dose of EBRT, several brachytherapy fractions, the location of the tumor in the left upper lobe, long sections of irradiated bronchi (clinical stage). The rate of fatal hemoptysis reported in the literature varies from $0 \%$ to $18.9 \%$ (Table 6). However, it is recognized by most authors that most fatal hemorrhage is not due to brachytherapy but to tumor progression $[24,60]$, and the rate is comparable to the incidence of hemoptysis after laser coagulation alone. Hennequin et al. [24] found no correlation with the site of the treatment, technical factors, fraction size, or associa-
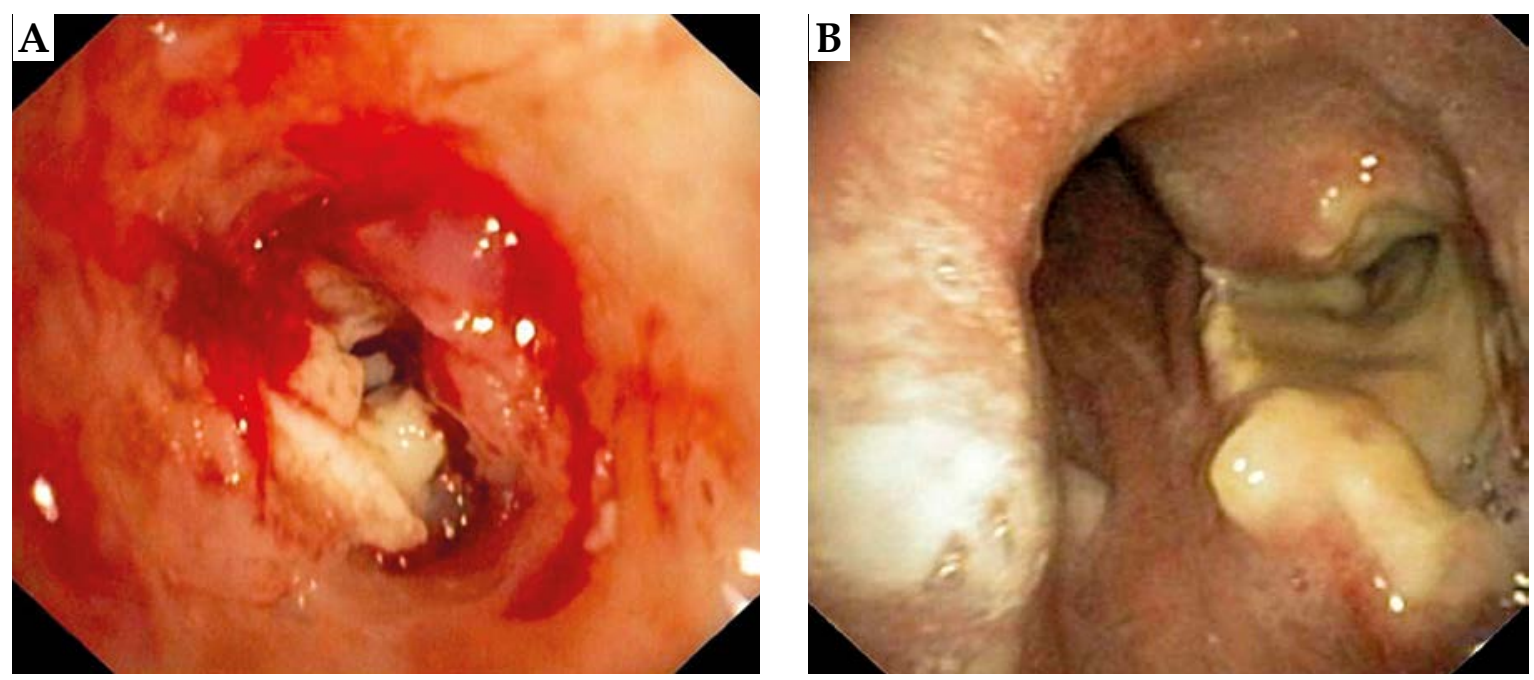

Fig. 12. A, B) Irradiation effects after brachytherapy - partial remission, superficial necrosis with residual tumor issue [own material] 
tion with EBRT as has been reported by others [59] but only with the length of endobronchial tumor spread. In the randomized trial conducted by the Munich group [51] however, fatal hemoptysis occurred more frequently after $2 \times 4.8$ Gy HDR boost than in patients who did not receive a boost after 60 Gy EBRT (18.9\% vs. 14.2\% fatal hemoptysis) but results were not statistically significance $(p=0.53)$.

The rate of tracheo-oesophageal fistula leading to death in the Macha [50] series is 5.3\% (mean 3.5 months after start of radiotherapy). To prevent fistula, it seems to be important to examine the bronchial wall (e.g. flat ulceration) and the oesophageal wall (oesophagoscopy) carefully in central tumors growing in this area. Oesophageal tumor infiltration carries a higher risk of developing fistula. Summarized observations are presented in Table 7.

Late effects such as chronic radiation bronchitis, bronchial stenosis, and tracheomalacia are of course only seen in long term survivors, most of them with lesions of the trachea or primary stem bronchus [24]. The incidence rates reported in the literature vary between 4 and 13\%. Speisser and Spratling [13] related chronic bronchitis to dose and dose rate (9\% in MDR and 13\% in HDR). Hennequin et al. [24] found a relation between chronic bronchitis and trachea, and main stem sites $(p=0.002)$, total dose $(p=0.04)$, and irradiated volume $(p=0.02)$, the latter being the only significant parameter in multivariate analysis.

Table 6. Incidence of massive hemoptysis after high-dose-rate endobronchial brachytherapy

\begin{tabular}{lccccc} 
Author & $N$ & Dose HDR* (Gy) & EBRT $^{* *}(n)$ & Reference point (mm) & Hemoptysis (\%) \\
\hline Nori et al. [71] & 32 & $3-4 \times 4-5$ & 32 & 10 & 0 \\
\hline Speiser and Spratling [13] & 295 & $3 \times 10,3 \times 7.5$ & 156 & 10 & 7 \\
\hline Chang et al. [55] & 76 & $3 \times 7$ & 59 & 10 & 4 \\
\hline Gollins et al. [72] & 406 & $1 \times 15-20$ & 82 & 10 & 7.9 \\
\hline Gustafson et al. [31] & 46 & $3 \times 7$ & 12 & 10 & 7 \\
\hline Hennequin et al. [24] & 149 & $4-6 \times 7$ & 112 & $5-15$ & 10.9 \\
\hline Huber et al. [51] & 56 & $2 \times 4.8$ & 56 & 10 & 10 \\
\hline Tredaniel et al. [27] & 51 & $1-6 \times 7$ & 32 & 10 & 11 \\
\hline Ornadel et al. [70] & 117 & $1 \times 15$ & 92 & 10 & 7 \\
\hline Taulelle et al. [4] & 189 & $3-4 \times 8-10$ & 117 & $6-7.5$ & 5 \\
\hline Kelly et al. [68] & 175 & $1-4 \times 15$ & 160 & 10 & 10 \\
\hline Miller and Phillips [64] & 88 & $3 \times 10$ & - & 62 & 15
\end{tabular}

*Number of fractions and fraction size in Gy, ${ }^{*} E B R T$ before BT or simultaneously EBRT - external beam radiation therapy, HDR-BT - high-dose-rate brachytherapy

Table 7. Incidence of fistulas after high-dose-rate and low-dose-rate brachytherapy

\begin{tabular}{|c|c|c|c|c|c|}
\hline Author & $n$ & Clinical stage & EBRT (Gy) & Brachytherapy schemas & Fistulas $(n, \%)$ \\
\hline Macha et al. [73] & 188 & Recurrence after EBRT & - & $3 \times 7.5 \mathrm{~Gy}$ & $15 / 188(8.0 \%)$ \\
\hline Harms et al. [10] & $\begin{array}{l}1.21 \\
2.34\end{array}$ & $\begin{array}{c}\text { 1. Recurrence after EBRT, } \\
\text { metastases } \\
\text { 2. Inoperable tumors }\end{array}$ & $\begin{array}{c}\text { 1. }- \\
\text { 2. } 30-60 \mathrm{~Gy}\end{array}$ & $\begin{array}{l}\text { 1. 5-27 Gy } \\
\text { 2. } 10-20 \mathrm{~Gy}\end{array}$ & $1 / 55(1.2 \%)$ \\
\hline Delclos et al. [67] & 81 & Recurrence after EBRT & - & $1-3 \times 1.5$ Gy (reference point at $6 \mathrm{~mm})$ & $1 / 81(1.2 \%)$ \\
\hline Cotter et al. [56] & 65 & Inoperable tumors & 55-66 Gy & $2-4 \times 2.7-10$ Gy & $3 / 65(4.6 \%)$ \\
\hline Kohek et al. [74] & 39 & $\||| A-\| \mid B$ & 50-70 Gy & $1-5 \times 5.6$ Gy & $(2.5 \%)$ \\
\hline Zajac et al. [58] & 24 & $\|\mathrm{~A}-\| \mathrm{II}$ & 50-61.2 Gy & $3 \times 5-10$ Gy & $(8 \%)$ \\
\hline Mehta et al. [65] & 23 & III & $61 \mathrm{~Gy}$ & LDR - 48 Gy & $\begin{array}{l}(6 \%)-T V \\
(3 \%)-T E\end{array}$ \\
\hline Sutedja et al. [75] & 31 & Inoperable tumors & - & $3 \times 10 \mathrm{~Gy}$ & $3 / 31(9.7 \%)$ \\
\hline Schray et al. [76] & 40 & Inoperable tumors & - & LDR - 30 Gy & $2 / 40(5 \%)$ \\
\hline
\end{tabular}

$T V$-tracheovascular fistula, TE-tracheoesophageal fistula, EBRT-external beam radiation therapy, HDR-high-dose-rate, LDR-low-dose-rate 


\section{Conclusions}

Brachytherapy palliative treatment in advanced lung cancer is an efficient method that results in most of the patients in improvement of quality of their lives. Brachytherapy is relatively easy to perform on outpatients basis. Brachytherapy plays a limited but specific role in definitive treatment with curative intent in selected cases of early endobronchial disease as well as in the postoperative treatment of small residual peribronchial disease.

\section{Acknowledgements}

Some data presented in this manuscript were published in my previous publications cited in the text.

\section{Disclosure}

Author reports no conflict of interest.

\section{References}

1. Skowronek J. Lung cancer brachytherapy. In: Lung cancer treatment. West BS, Stanley DR (eds.). Nova Science, New York 2011

2. Stephens KE Jr, Wood DE. Bronchoscopic management of central airway obstruction. J Thorac Cardiovasc Surg 2000; 119 . 289-296.

3. Sutedja G, Baris G, van Zadwijk N et al. High-dose rate brachytherapy has a curative potential in patients with intraluminal squamous cell lung cancer. Respiration 1993; 61: 167168.

4. Taulelle M, Chauvet B, Vincent $P$ et al. High dose rate endobronchial brachytherapy: results and complications in 189 patients. Eur Respir J 1998; 11: 162-168.

5. Skowronek J, Piotrowski T, Młynarczyk W et al. Advanced tracheal carcinoma - a therapeutic significance of HDR brachytherapy in palliative treatment. Neoplasma 2004; 51: 313 318.

6. Skowronek J, Kubaszewska M, Kanikowski M et al. HDR endobronchial brachytherapy (HDRBT) in the management of advanced lung cancer - comparison of two different dose schedules. Radiother Oncol 2009; 93: 436-440.

7. Fijuth J. HDR endobronchial brachytherapy in palliative and combined radical treatment of lung cancer. J Contemp Brachyther 2009; 4: 231-236.

8. Skowronek J, Młynarczyk W, Piorunek T. Brachyterapia raka tchawicy i płuca - wskazania, metody, wyniki leczenia. Przegl Lek 2006; 63: 664-673 [in Polish].

9. Skowronek J, Piotrowski T, Ramlau R et al. The repeated use of High Dose Rate Brachytherapy to palliate symptomatic recurrence of lung cancer. Rep Pract Radioth Oncol 2003; 4 : 127-137.

10. Harms W, Schraube P, Becker $H$ et al. Effect and toxicity of endoluminal high-dose-rate (HDR) brachytherapy in centrally located tumors of the upper respiratory tract. Strahlenther Onkol 2000; 176: 60-66.

11. Macha HN, Freitag L. The role of brachytherapy in the treatment and control of central bronchial carcinoma. Monaldi Arch Chest Dis 1996; 51: 325-328.

12. Gaspar LE. Brachytherapy in lung cancer. J Surg Oncol 1998; 67: 60-70.

13. Speiser BL, Spratling L. Remote afterloading brachytherapy for the local control of endobronchial carcinoma. Int J Radiat Oncol Biol Phys 1993; 25: 579-587.
14. Kasprowicz A, Łyczek J, Kulik A et al. Paliatywna jednofrakcyjna brachyterapia HDR w leczeniu zaawansowanego miejscowo raka oskrzeli. Nowotwory 1999; 49: 35-38 [in Polish].

15. Kubaszewska M, Skowronek J, Chicheł A et al. The use of high dose rate endobronchial brachytherapy to palliate symptomatic recurrence of previously irradiated lung cancer. Neoplasma 2008; 3: 239-245.

16. Skowronek J, Piorunek T, Kanikowski M et al. Definitive high-dose-rate endobronchial brachytherapy of bronchial stump for lung cancer after surgery. Brachytherapy 2013; 12: 560-566.

17. The GEC ESTRO Handbook of Brachytherapy. Gerbaulet A, Potter R, Mazeron J-J, Meertens H, Van Limbergen E (eds.). ESTRO, Bruksela 2002.

18. Senan S, Lagerwaard, FJ, de Pan C, on behalf of the Rotterdam Oncological Thoracic Study Group. A CT-assisted method of dosimetry in brachytherapy of lung cancer. Radiother Oncol 2000; 55: 75-80.

19. Sutejda G, Baris G, Schaake-Koning C et al. High dose rate brachytherapy in patients with local recurrences after radiotherapy of non-small cell lung cancer. Int J Radiat Oncol Biol Phys 1992; 24: 551-553.

20. Huber RM, Fischer R, Hautmann $\mathrm{H}$ et al. Does additional brachytherapy improve the effect of external irradiation? A prospective, randomized study in central lung tumors. Int J Radiat Oncol Biol Phys 1997; 38 : 533-540.

21. Fuwa N, Ito $Y$, Kato E et al. The role of endobronchial irradiation as a curative therapy. J Jpn Soc Ther Radiol Oncol 1997; 9: 55-61.

22. Saito M, Yokoyama A, Kurita Y et al. Treatment of roentgenographically occult endobronchial carcinoma with external beam radiotherapy and intraluminal LDR brachytherapy. A second report. Int J Radiat Oncol Biol Phys 2000; 47: 673-680.

23. Ardiet JM, Pommier P, Coquard R et al. Curative irradiation for limited non-small cell lung cancer with exclusive high dose rate brachytherapy (Abstr.). Radiother Oncol 1994; 31 (Suppl 1): 46.

24. Hennequin C, Tredaniel J, Chevret S et al. Predictive factors for late toxicity after endobronchial brachytherapy: a multivariate analysis. Int J Radiat Oncol Biol Phys 1998; 42: 21-27.

25. Marsiglia H, Baldeyrou P, Lartigau E et al. A. high-dose rate brachytherapy as sole modality for early stage endobronchial carcinoma. Int J Radiat Oncol Biol Phys 2000; 20: 665-672.

26. Perol M, Caliandro R, Pommier P et al. Curative irradiation of limited endobronchial carcinomas with high-dose rate brachytherapy. Chest 1997; 111: 1417-23.

27. Tredaniel J, Hennequin C, Zaleman G et al. Prolonged survival after high-dose rate endobronchial radiation for malignant airway obstruction. Chest 1994; 105: 767-772.

28. Fuwa N, Matsumoto A, Kamata M et al. External irradiation and intraluminal irradiation using middle-dose-rate iridium in patients with roentgenographically occult lung cancer. Int J Radiat Oncol Biol Phys 2001; 49: 965-971.

29. Nag S, Kelly JF, Horton JL et al. The American Brachytherapy Society recommendations for brachytherapy of carcinoma of the lung, Proceedings of the 42nd Annual ASTRO Meeting. Int J Radiat Oncol Biol Phys 2000; 48: S328.

30. Mantz CA, Dosoretz DE, Rubenstein JH et al. Endobronchial brachytherapy and optimization of local disease control in medically inoperable non-small cell lung carcinoma: A matched-pair analysis. Brachytherapy 2004; 3: 183-190.

31. Gustafson G, Vincini F, Freedman L et al. High dose rate endobronchial brachytherapy in the management of primary and recurrent bronchogenic malignancies. Cancer 1995; 75: 2345-2350. 
32. Harms W, Latz D, Becker H et al. HDR-brachytherapy boost for residual tumour after external beam radiotherapy in patients with tracheal malignancies. Radioth Oncol 1999; 52 251-255.

33. Harms W, Latz D, Becker $\mathrm{H}$ et al. Treatment of primary tracheal carcinoma. The role of external and endoluminal radiotherapy. Strahlenther Onkol 2000; 176: 22-27.

34. Seagren SL, Harrell JH, Horn RA. High dose rate intraluminal irradiation in recurrent endobronchial carcinoma. Chest 1985; 88: 810-814.

35. Sawicki M, Kazalski M, Łyczek J et al. The evaluation of treatment plans in high-dose-rate endobronchial brachytherapy by utilizing 2D and 3D computed tomography imaging methods. J Contemp Brachytherapy 2014; 6: 289-292.

36. Łyczek J, Kazalski D, Kowalik $€$ et al. Comparison of the GTV coverage by PTV and isodose of $90 \%$ in 2D and 3D planning Turing endobronchial brachytherapy in the palliative treatment of patients with advanced lung cancer. J Contemp Brachytherapy 2012; 4: 113-115.

37. Mutyala S, Stewart A, Khan AJ et al. Permanent iodine-125 interstitial planar seed brachytherapy for close or positive margins for thoracic malignancies. Int J Radiat Oncol Biol Phys 2010; 76: 1114-1120.

38. Fleishman EH, Kaagan AR, Streeter OE et al. Iodine-125 interstitial brachytherapy in the treatment of carcinoma of the lung. J Surg Oncol 1992; 49: 25-28.

39. Hilaris BS, Martini N, Wong GY et al. Treatment of superior sulcus tumor (Pancoast tumor). Surg Clin North Am 1987; 67: 965-977.

40. Hilaris BS, Nori D, Martini N. Intraoperative radiotherapy in stage I and II lung cancer. Semin Surg Oncol 1987; 3: 22-30.

41. Stewart AJ, Mutyala S, Holloway CL et al. Intraoperative seed placement for thoracic malignancy. A review of technique, indications, and published literature. Brachytherapy 2009; 8: 63-69.

42. Chen A, Galloway M, Landreneau R et al. Intraoperative 125I brachytherapy for high-risk stage I non-small cell lung carcinoma. Int I Radiat Oncol Biol Phys 1999; 44: 1057-1063.

43. d'Amato TA, Galloway M, Szijdlowski G et al. Intraoperative Brachytherapy Following Thoracoscopic Wedge Resection of Stage I Lung Cancer. Chest 1998; 114: 1112-1115.

44. Trombetta MG, Colonias A, Makishi D et al. Tolerance of the aorta using intraoperative iodine-125 interstitial brachytherapy in cancer of the lung. Brachytherapy 2008; 7: 50-54.

45. Hänninen EL, Felix R, Ricke J et al. Results of a Novel Technique Brachytherapy of Lung Tumors: Phase I CT-Guided Interstitial Single-Fraction. Chest 2005; 127: 2237-2242.

46. Hilaris BS, Nori D, Beattie EJ Jr. et al. Value of perioperative brachytherapy in the management of non-oat cell carcinoma of the lung. Int J Radiat Oncol Biol Phys 1983; 9: 1161-1166.

47. Lagerwaard FJ, Murrer LHP, de Pan C et al. Mucosal dose prescription in endobronchial brachytherapy: a study based on CT-dosimetry. Int J Radiat Oncol Biol Phys 2000; 46: 1051-1059.

48. Shahabi S, Mehta M, Wiley Al et al. The role of computed tomography in dosimetric evaluation of endobronchial implants. Endocurie Hyperther Oncol 1988; 4: 187-191.

49. Skowronek J. CT-Image Guided Brachytherapy. In: Theory and Applications of CT Imaging and Analysis. Homma N (ed.). Intech, Austria 2011.

50. Macha HN, Wahlers B, Reichle C et al. Endobronchial radiation therapy for obstructing malignancies: ten years' experience with iridium-192 high-dose radiation brachytherapy afterloading technique in 365 patients. Lung 1995; 173: 271-280.

51. Huber RM, Fischer R, Hautmann H. Palliative endobronchial brachytherapy for central lung tumors. A prospective, randomized comparison of two fractionation schedules. Chest 1995; 107: 463-470.
52. Reddi RP, Marbach JC. HDR remote afterloading brachytherapy of carcinoma of the lung. Selectron Brachyther J1992; 6: 21-23.

53. Aygun, C, Weiner S, Scariato A et al. Treatment of non-small cell lung cancer with external beam radiotherapy and high dose rate brachytherapy. Int J Radiat Oncol Biol Phys 1992; 23: 127-132.

54. Mehta MP, Shahabi S, Jarjour NN et al. Endobronchial irradiation for malignant airway obstruction. Int J Radiat Oncol Biol Phys 1989; 17: 847-851.

55. Chang Li-Fen L, Horvath J, Peyton W et al. High dose rate afterloading intraluminal brachytherapy in malignant airway obstruction of lung cancer. Int J Radiat Oncol Biol Phys 1994; 28: 589-596.

56. Cotter GW, Lariscy C, Ellingwood KE et al. Inoperable endobronchial obstructing lung cancer treated with combined endobronchial and external beam irradiation: a dosimetric analysis. Int J Radiat Oncol Biol Phys 1993; 27: 531-535.

57. Kohek P, Pakisch B, Rehak et al. Nd-YAG laser debulking combined with Ir 192 HDR brachytherapy for obstructing cancer of the central bronchial airways: technique and results. Activity 1990; Suppl 1: 45-47.

58. Zajac AJ, Kohn ML, Heiser D et al. High-dose-rate intraluminal brachytherapy in the treatment of endobronchial malignancy. Radiology 1993; 187: 571-575.

59. Gollins SW, Burt PA, Barber PV et al. Long term survival and symptom palliation in small primary bronchial carcinomas following treatment with Intraluminal Radiotherapy alone. Clin Oncol 1996; 8: 239-246.

60. Bedwinek JM, Petty A, Bruton C et al. The use of high dose rate endobronchial brachytherapy to palliate symptomatic endobronchial recurrence of previously irradiated bronchogenic carcinoma. Int J Radiat Oncol Biol Phys 1991; 22: 23-30.

61. Jacobson MJ, LoCicero J. Endobronchial treatment of lung carcinoma. Chest 1991; 100: 838-841.

62. Gauwitz M, Ellerbroek N, Komaki R et al. High dose endobronchial irradiation in recurrent bronchogenic carcinoma. Int J Radiat Oncol Biol Phys 1992; 23: 397-400.

63. Burt PA, O'Driscoll BR, Notley HM et al. Intraluminal irradiation for the palliation of lung cancer with high dose rate microselectron. Thorax 1990; 45: 765-768.

64. Miller JI Jr, Philips TW. Neodymium: YAG laser and brachytherapy in the management of inoperable bronchogenic carcinoma. Ann Thorac Surg 1990; 50: 190-196.

65. Mehta M, Petereit D, Chosy L et al. Sequential comparison of low dose rate and hyperfractionated high dose rate endobronchial radiation for malignant airway occlusion. Int J Radiat Oncol Biol Phys 1992; 23: 133-139.

66. Speiser B, Spratling L. Intermediate dose rate remote afterloading brachytherapy for intraluminal control of bronchogenic carcinoma. Int J Radiat Oncol Biol Phys 1990; 18: 1443-1448.

67. Delclos ME, Komaki R, Morice RC et al. Endobronchial brachytherapy with high-dose rate remote afterloading for recurrent endobronchial lesions. Radiology 1996; 201: 279-282.

68. Kelly JF, Delclos ME, Morice RC et al. High-dose-rate endobronchial brachytherapy effectively palliates symptoms due to airway tumors: the 10-years M.D. Anderson Cancer Center experience. Int J Radiat Oncol Biol Phys 2000; 48: 697-702.

69. Micke O, Prott FJ, Schäfer U et al. Endoluminal HDR brachytherapy as a palliative treatment of patients with recurrent previously irradiated non-small cell lung carcinoma. Strahlenther Onkol 1995; 171: 554-559.

70. Ornadel D, Duchesne G, Wall P et al. Defining the roles of high dose rate endobronchial brachytherapy and laser resection for recurrent bronchial malignancy. Lung Cancer 1997; 16: 203-213.

71. Nori D, Allison R, Kaplan B. High dose rate intraluminal irradiation in bronchogenic carcinoma. Chest 1993; 104: 10061011. 
72. Gollins SW, Ryder WDJ, Burt PV. Massive haemoptysis death and other morbidity associated with high dose rate intraluminal radiotherapy for carcinoma of the bronchus. Radiother Oncol 1996; 39: 105-116.

73. Macha HN, Koch K, Stadler M et al. The therapeutic possibilities of the combination of laser resection and the afterloading technique as seen by the endoscopist. Tumor Diagn Ther 1986; 7: 39-41.

74. Kohek PH, Pakish B, Glanzer H. Intraluminal irradiation in the treatment of malignant airway obstruction. Eur J Surg Oncol 1994; 20: 674-680.

75. Sutedja G, Baris G, Schaake-Koning C et al. High dose rate brachytherapy in patients with local recurrences after radiotherapy of non-small cell lung cancer. Int J Radiat Oncol Biol Phys 1992; 24: 551-553.

76. Schray MF, Martinez A, McDougall JC. Malignant airway obstruction: management with temporary intraluminal brachytherapy and laser treatment. Endocuriether Hypertherm Oncol 1985; 1: 237-245. 